\title{
Predicting 90-day and long-term mortality in octogenarians undergoing radical cystectomy
}

\author{
Michael Froehner ${ }^{1 *}$, Rainer Koch², Matthias Hübler ${ }^{3}$, Ulrike Heberling $^{1}$, Vladimir Novotny ${ }^{1}$, Stefan Zastrow ${ }^{1}$, \\ Oliver W. Hakenberg ${ }^{4}$ and Manfred P. Wirth ${ }^{1}$
}

\begin{abstract}
Background: Radical cystectomy bears a considerable perioperative mortality risk particularly in elderly patients. In this study, we searched for predictors of perioperative and long-term competing (non-bladder cancer) mortality in elderly patients selected for radical cystectomy.

Methods: We stratified 1184 consecutive patients who underwent radical cystectomy for high risk superficial or muscle-invasive urothelial or undifferentiated carcinoma of bladder into two groups (age $<80$ years versus 80 years or older). Multivariable and cox proportional hazards models were used for data analysis.

Results: Whereas Charlson score and the American Society of Anesthesiologists (ASA) physical status classification (but not age) were independent predictors of 90-day mortality in younger patients, only age predicted 90-day mortality in patients aged 80 years or older (odds ratio per year 1.24, $p=0.0422$ ). Unlike in their younger counterparts, neither age nor Charlson score or ASA classification were predictors of long-term competing mortality in patients aged 80 years or older (hazard ratios 1.07-1.10, $p$ values 0.21-0.77).

Conclusions: This data suggest that extrapolations of perioperative mortality or long-term mortality risks of younger patients to octogenarians selected for radical cystectomy should be used with caution. Concerning 90-day mortality, chronological age provided prognostic information whereas comorbidity did not.
\end{abstract}

Keywords: Bladder cancer, Radical cystectomy, 90-day mortality, Competing mortality, Comorbidity, Age

\section{Background}

Radical cystectomy bears a considerable perioperative mortality risk particularly in elderly patients [1-5]. Robot-assisted surgery has been evaluated as a novel technique in order to decrease adverse outcome in elderly patients [6]. Currently, there is, however, still insufficient evidence to prefer any approach to radical cystectomy [7]. Elderly patients tend to be treated less aggressively although they may benefit from such treatment similarly as their younger counterparts $[8,9]$. Since patients with a long remaining life expectancy and a low risk of perioperative mortality are more likely to benefit from radical surgery, identifying those patients could

\footnotetext{
* Correspondence: Michael.Froehner@uniklinikum-dresden.de

'Department of Urology, University Hospital Carl Gustav Carus, Technische

Universität Dresden, Fetscherstrasse 74, D-01307 Dresden, Germany

Full list of author information is available at the end of the article
}

improve disease management. Until now, few tools are available in order to estimate the postoperative and long-term competing mortality risks in octogenarian candidates for radical cystectomy [1-5, 7-9].

\section{Methods}

\section{Study sample}

We studied a sample of 1184 consecutive patients who underwent radical cystectomy for high risk superficial or muscle-invasive urothelial or undifferentiated carcinoma of bladder at our institution between 1993 and 2015. Institutional review board approval was obtained (EK84032009). The patients were stratified into two groups by an a priori chosen cutoff (age $<80$ years versus 80 years or older). Demographic data is given in Table 1.

(C) The Author(s). 2018 Open Access This article is distributed under the terms of the Creative Commons Attribution 4.0 International License (http://creativecommons.org/licenses/by/4.0/), which permits unrestricted use, distribution, and 
Table 1 Demographic data of the study population in all patients, patients aged 80 years or older and patients younger than 80 years. Comorbidity profile and tumor-related parameters as well as 90-day mortality and 5-year bladder cancer specific and competing mortality rates were less favorable in patients aged 80 years or older compared with their younger counterparts

\begin{tabular}{|c|c|c|c|c|}
\hline Parameter & Whole sample & $<80$ years & 80 years or older & $p$ \\
\hline Sample size & 1184 & 1061 & 123 & - \\
\hline Mean follow-up (censored patients) & 7.4 years & 7.6 years & 3.8 years & - \\
\hline Median follow-up (censored patients) & 6.2 years & 6.5 years & 2.5 years & - \\
\hline Mean age & 68.7 years & 67.1 years & 82.6 years & - \\
\hline Bladder confined disease & $684(58 \%)$ & $629(59 \%)$ & $55(45 \%)$ & 0.0020 \\
\hline Extravesical extension & $500(42 \%)$ & $432(41 \%)$ & $68(55 \%)$ & 0.0020 \\
\hline Positive lymph nodes & $308(26 \%)$ & $272(26 \%)$ & $36(29 \%)$ & 0.38 \\
\hline Extravesical extension or positive lymph nodes & $576(49 \%)$ & $500(47 \%)$ & $76(62 \%)$ & 0.0021 \\
\hline Bladder confined disease and negative lymph nodes & $608(51 \%)$ & $561(53 \%)$ & $47(38 \%)$ & 0.0021 \\
\hline ASA classes 3-4 & $493(42 \%)$ & $421(40 \%)$ & $72(59 \%)$ & $<0.0001$ \\
\hline Charlson score 2 or higher & $449(38 \%)$ & $383(36 \%)$ & $66(54 \%)$ & 0.0001 \\
\hline Mean Charlson score & 1.57 & 1.50 & 2.18 & $<0.0001$ \\
\hline Median Charlson score & 1.00 & 1.00 & 2.00 & - \\
\hline CCS class 2 or higher & $131(11 \%)$ & $109(10 \%)$ & $22(18 \%)$ & 0.0108 \\
\hline NYHA class 2 or higher & $211(18 \%)$ & $177(17 \%)$ & $34(28 \%)$ & 0.0026 \\
\hline Female patients & $255(22 \%)$ & $206(19 \%)$ & $49(40 \%)$ & $<0.0001$ \\
\hline Any neoadjuvant chemotherapy & $55(5 \%)$ & $53(5 \%)$ & $2(2 \%)$ & 0.09 \\
\hline Adjuvant cisplatin-based chemotherapy & $258(22 \%)$ & $257(24 \%)$ & $1(1 \%)$ & $<0.0001$ \\
\hline Current smokers & $327(28 \%)$ & $315(30 \%)$ & $12(10 \%)$ & $<0.0001$ \\
\hline University degree/master craftsman & $274(23 \%)$ & $250(24 \%)$ & $24(20 \%)$ & 0.31 \\
\hline Mean body mass index & $27.0 \mathrm{~kg} / \mathrm{m}^{2}$ & $27.0 \mathrm{~kg} / \mathrm{m}^{2}$ & $26.7 \mathrm{~kg} / \mathrm{m}^{2}$ & 0.26 \\
\hline Median body mass index & $26.7 \mathrm{~kg} / \mathrm{m}^{2}$ & $26.7 \mathrm{~kg} / \mathrm{m}^{2}$ & $26.4 \mathrm{~kg} / \mathrm{m}^{2}$ & - \\
\hline Continent diversion & $390(33 \%)$ & $388(37 \%)$ & $2(2 \%)$ & $<0.0001$ \\
\hline Number of removed lymph nodes (if recorded) & 18.4 & 18.8 & 15.2 & $<0.0001$ \\
\hline History of myocardial infarction & $86(7 \%)$ & $72(7 \%)$ & $14(11 \%)$ & 0.06 \\
\hline Diabetes mellitus & $288(24 \%)$ & $250(24 \%)$ & $38(31 \%)$ & 0.07 \\
\hline Lung disease & $218(18 \%)$ & $196(18 \%)$ & $22(18 \%)$ & 0.87 \\
\hline Cerebrovascular disease & $65(5 \%)$ & $56(5 \%)$ & $9(7 \%)$ & 0.35 \\
\hline Peripheral vascular disease & $129(11 \%)$ & $111(10 \%)$ & $18(15 \%)$ & 0.16 \\
\hline Deaths from non-cancer causes & 205 & 170 & 35 & - \\
\hline Deaths from bladder cancer & 372 & 325 & 47 & - \\
\hline Deaths from second cancer & 66 & 64 & 2 & - \\
\hline Deaths from unknown causes & 7 & 5 & 2 & - \\
\hline 90-day mortality & $4.2 \%$ & $3.7 \%$ & $8.9 \%$ & $<0.0001$ \\
\hline 5-year bladder cancer-specific mortality & $30.3 \%$ & $28.9 \%$ & $44.3 \%$ & 0.0038 \\
\hline 5-year competing (non-bladder cancer) mortality & $14.1 \%$ & $12.5 \%$ & $28.7 \%$ & 0.0005 \\
\hline
\end{tabular}

CCS Classification of angina pectoris of the Canadian Cardiovascular Society [21]; NYHA Classification of cardiac insufficiency of the New York Heart Association [22]; ASA American Society Association physical status classification [11]

Variables and data collection

Beside age as a continuous variable, numeric comorbidity (measured by the Charlson score [10]) and the clinical impression of the patient (measured by the American Society of Anesthesiologists (ASA) physical status classification
[11]) (Table 2) and - concerning long-term competing (non-bladder cancer) mortality - a variety of single conditions were analyzed as possible predictors of outcome (Table 3). Comorbidity data was obtained from premedication records and discharge documents. Follow-up 
Table 2 A: Optimal multivariable logit models predicting 90-day mortality and B: Optimal multivariable proportional hazard models predicting non-bladder cancer (competing) mortality with 95\% confidence intervals and $p$ values in all patients, patients aged 80 years or older and patients younger than 80 years including the variables age, Charlson score and ASA classification

\begin{tabular}{|c|c|c|c|c|c|c|}
\hline & Whole sample & & $<80$ years & & $80+$ years & \\
\hline \multicolumn{7}{|l|}{ A: Endpoint 90-day mortality } \\
\hline Parameter & OR $(95 \% \mathrm{Cl})$ & $p$ & OR $(95 \% \mathrm{Cl})$ & $p$ & OR $(95 \% \mathrm{Cl})$ & p \\
\hline Age (continuous variable, per year) & $1.05(1.01-1.09)$ & 0.0106 & n. s.* & & $1.24(1.01-1.51)$ & 0.0422 \\
\hline Charlson-Score (continuous variable, per point) & $1.16(1.02-1.31)$ & 0.0197 & $1.22(1.07-1.39)$ & 0.0029 & n. s. ${ }^{* *}$ & \\
\hline ASA classes 3-4 (versus classes 1-2) & $6.95(2.80-17.2)$ & $<0.0001$ & $9.28(3.11-27.8)$ & $<0.0001$ & n. s. ${ }^{* *}$ & \\
\hline \multicolumn{7}{|l|}{ B: Endpoint non-bladder-cancer (competing) mortality } \\
\hline Parameter & HR $(95 \% \mathrm{Cl})$ & $p$ & HR $(95 \% \mathrm{Cl})$ & $p$ & HR $(95 \% \mathrm{Cl})$ & $p$ \\
\hline Age (continuous variable, per year) & $1.04(1.02-1.05)$ & $<0.0001$ & $1.04(1.02-1.06)$ & $<0.0001$ & n. s. ${ }^{* * *}$ & \\
\hline Charlson-Score (continuous variable, per point) & $1.17(1.02-1.24)$ & $<0.0001$ & $1.18(1.11-1.26)$ & $<0.0001$ & n. s. ${ }^{* * *}$ & \\
\hline ASA classes 3-4 (versus classes 1-2) & $1.59(1.21-2.08)$ & 0.0008 & $1.67(1.25-2.25)$ & 0.0006 & n. s. ${ }^{* * *}$ & \\
\hline
\end{tabular}

ASA American Society Association physical status classification [11]; OR Odds ratio; HR Hazard ratio; Cl Confidence interval; $n$. s. Not significant. *Full model: age: OR 1.04 (0.99-1.09), $\mathrm{p}=0.14$, Charlson score: OR 1.21 (1.06-1.38), $p=0.0050$, ASA classes 3-4: OR 8.48 (2.83-25.40), $p=0.0001$. **Full model: age: OR 1.18 (0.97-1.48), $p=0.10$, Charlson score: OR 0.90 (0.61-1.34), $p=0.60$, ASA classes 3-4: OR 3.45 (0.66-17.95), $p=0.14$. ***Full model: age: HR 1.08 (0.96-1.22), $p=0.21$, Charlson score: HR 1.07 (0.96-1.27), $p=0.41$, ASA classes 3-4: HR 1.10 (0.58-2.09), $p=0.77$

Table 3 Optimal multivariable proportional hazard models with 95\% confidence intervals and p values for competing risks predicting competing in all patients, patients aged 80 years or older and patients younger than 80 years, respectively investigating single conditions as possible predictors of competing mortality. Only single conditions occurring in at least 5 patients were included in the analysis

\begin{tabular}{|c|c|c|c|c|c|c|}
\hline \multirow[b]{2}{*}{ Parameter } & \multicolumn{2}{|l|}{ Whole sample } & \multicolumn{2}{|l|}{$<80$ years } & \multicolumn{2}{|l|}{$80+$ years } \\
\hline & $\mathrm{HR}(95 \% \mathrm{Cl})$ & $p$ & $\mathrm{HR}(95 \% \mathrm{Cl})$ & $p$ & $\mathrm{HR}(95 \% \mathrm{Cl})$ & $p$ \\
\hline Age (continuous variable, per year) & $1.05(1.03-1.06)$ & $<0.0001$ & $1.06(1.04-1.08)$ & $<0.0001$ & & \\
\hline Angina pectoris (CCS classes 2-4 versus 0-1) & & & $1.89(1.37-2.61)$ & 0.0001 & & \\
\hline \multicolumn{7}{|l|}{ Hypertension (versus none) } \\
\hline \multicolumn{7}{|l|}{ History of thromboembolism (versus none) } \\
\hline Myocardial infarction (versus none) & $1.74(1.21-2.51)$ & 0.0029 & & & $2.20(1.05-4.62)$ & 0.0357 \\
\hline \multicolumn{7}{|c|}{ Cardiac insufficiency (NYHA classes 2-4 versus 0-1) } \\
\hline \multicolumn{7}{|l|}{ Peripheral vascular disease (versus none) } \\
\hline \multicolumn{7}{|l|}{ Cerebrovascular disease (versus none) } \\
\hline Chronic lung disease (versus none) & $1.41(1.06-1.88)$ & 0.0167 & & & & \\
\hline \multicolumn{7}{|l|}{ Ulcer disease (versus none) } \\
\hline Diabetes mellitus (versus none) & $1.45(1.12-1.88)$ & 0.0051 & $1.37(1.04-1.82)$ & 0.0261 & & \\
\hline \multicolumn{7}{|l|}{ Connective tissue disease (versus none) } \\
\hline \multicolumn{7}{|l|}{ Hemiplegia (versus none) } \\
\hline \multicolumn{7}{|l|}{ Moderate or severe renal disease (versus none) } \\
\hline \multicolumn{7}{|l|}{ Solid tumor, leukemia or lymphoma (versus none) } \\
\hline Liver disease (versus none) & & & $2.38(1.25-4.54)$ & 0.0081 & & \\
\hline \multicolumn{7}{|l|}{ Dementia (versus none) } \\
\hline Current smoker (versus ex-/non-smokers ${ }^{\mathrm{a}}$ ) & $1.58(1.21-2.07)$ & 0.0008 & $1.75(1.34-2.30)$ & $<0.0001$ & & \\
\hline \multicolumn{7}{|l|}{ Body mass index $<25 \mathrm{~kg} / \mathrm{m}^{2}$ (versus $25+\mathrm{kg} / \mathrm{m}^{2}$ ) } \\
\hline ASA class 3-4 (versus classes 1-2) & $1.68(1.30-2.18)$ & $<0.0001$ & $1.77(1.34-2.34)$ & $<0.0001$ & & \\
\hline Male sex (versus female) & & & $1.75(1.18-2.62)$ & 0.0052 & & \\
\hline
\end{tabular}


data were collected from urologists, general practitioners, the patients and their relatives, health insurance companies, local authorities and the local tumor register. All patients were observed for at least 90 days after surgery. Bladder cancer was considered the cause of death when uncontrolled disease progression was present at the time of death. Deaths from causes other than bladder cancer or unknown causes $(n=7)$ were considered deaths from competing causes. 90-day mortality (from all causes) and competing (non-bladder cancer) mortality were the study endpoints.

\section{Statistical analyses}

Concerning 90-day mortality, complete information for each patient (yes or no) was available. Multivariable logit models were used for the identification of predictors of 90-day mortality. Non-bladder cancer (competing) mortality was calculated from incomplete observations with censoring (and of observation in patients still alive) and competing (deaths from bladder cancer) events. Proportional hazard models for competing risks were used for the identification of predictors of non-bladder cancer (competing) mortality. Because of the limited number of events available for 90-day mortality, we dispensed from an analysis of multiple single conditions for this endpoint as done with long-term non-bladder cancer (competing) mortality (Table 3). The analyses were done with the Statistical Analysis Systems V9.4 statistical package (SAS Institute, Cary, NC).

\section{Results}

Tumor-associated parameters (proportion of extravesical extension or positive lymph nodes), 5-year bladder cancer-specific mortality, 90-day mortality and non-bladder cancer (competing) mortality were less favorable in the octogenarian subgroup (Table 1). Octogenarians were more frequently female, less frequently current smokers, had a higher burden of comorbidity and did only rarely receive adjuvant and neoadjuvant chemotherapy (Table 1). Cumulative mortality curves from bladder cancer and from causes other than bladder cancer (competing causes) are shown in Fig. 1. Both types of mortality were higher in octogenarians compared with their younger counterparts (Fig. 1).

Whereas in younger patients the comorbidity measures Charlson score and ASA classification (but not age) were independent predictors of 90-day mortality, in those aged 80 years or older only chronological age was an independent predictor of 90-day mortality (Table 2). Remarkably, despite the range restriction of this variable in patients aged 80 years or older, chronological age became only an independent predictor of 90-day mortality after inclusion of this subgroup (Table 2).

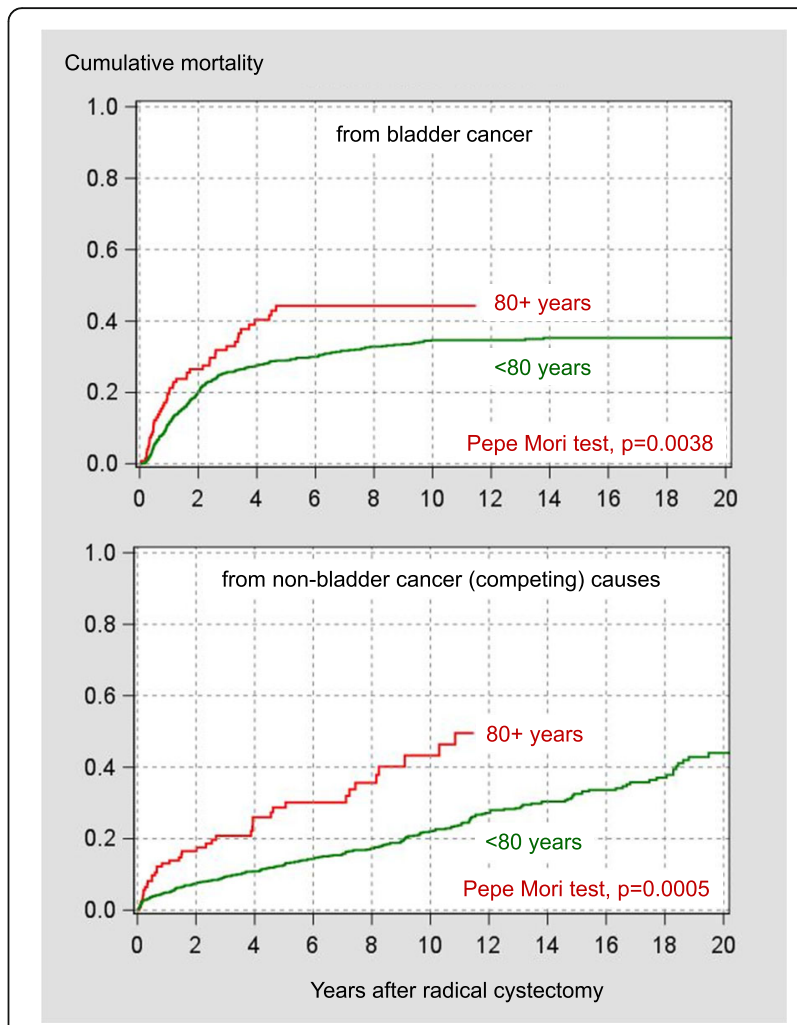

Fig. 1 Cumulative mortality curves from bladder cancer and from causes other than bladder cancer (competing causes) stratified by the age cutoff of 80 years

Whereas in younger patients age, Charlson score and ASA classification were independent predictors of long-term competing mortality with $p$ values $<0.001$, all three parameters were far apart from the significance level in patients aged 80 years or older (Table 2). In contrast, in younger patients, the ASA classification was of distinct and probably clinically meaningful impact on 90-day and long-term competing mortality after radical cystectomy in younger patients (Tables 2 and 3, Fig. 2). When single conditions were analyzed, in patients younger than 80 years a complex model containing age and six comorbidity-related variables predicted long-term competing mortality whereas in their older counterparts only one variable (history of myocardial infarction) was a significant predictor (Table 3).

\section{Discussion}

This study suggests that extrapolations of 90-day mortality or long-term competing mortality risks of younger patients to octogenarians selected for radical cystectomy should be used with caution. Concerning 90-day mortality, in octogenarians selected for radical cystectomy chronological age could have greater impact than numeric comorbidity. In the full model predicting 90-day mortality in patients aged 80 years or older, the odds 


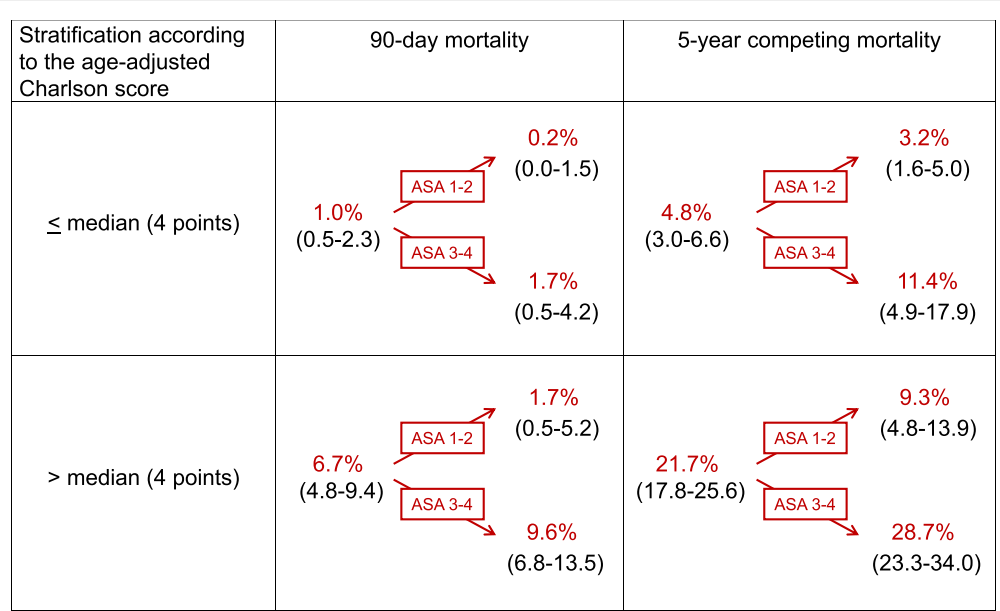

Fig. 2 Impact of the stratification of patients younger than 80 years by the ASA classification on 90-day mortality and 5-year competing (non-bladder cancer) mortality rates after primary stratification by the age-adjusted Charlson score [16] (in brackets: $95 \%$ confidence intervals). Within the same risk group indicated by the age-adjusted Charlson score, the 90 -day mortality differed by the factor 5-8 and 5-year competing mortality differed approximately by the factor 3 between patients with an ASA class 1-2 versus those with a ASA class 3-4. Such large differences are probably relevant for clinical decision making. For age-adjustment of the Charlson score, 1 point is added for an age of 50-59 years, 2 points for an age of 60-69 years, 3 points for an age of 70-79 years, 4 points for an age of 80-89 years and 5 points for an age of 90-99 years [16]

ratio of the Charlson score was lower than 1 indicating the loss of prognostic impact of numeric comorbidity (in contrast to findings in other types of cancer surgery [12]), whereas the ASA class with an odds ratio of 3.45 (95\% confidence interval 0.66-17.95) sustained some of its prognostic impact visible in younger patients (Table 2). It is conceivable that with a larger sample size this classification might reach the significance level in the elderly subgroup as well.

Comorbidity has been found associated with perioperative death 90-day mortality and 5-year mortality after radical cystectomy [13, 14]. Nomograms have been developed and validated predicting all-cause mortality including variables related to age and comorbidity measured by the Charlson score [15].

In the current study, in patients younger than 80 years, particularly the ASA classification was of distinct and probably clinically meaningful impact on 90-day and long-term competing mortality after radical cystectomy in younger patients (Fig. 2). Whereas the 2017 guidelines of the American Urological Association (AUA) dispensed from detailed recommendations on comorbidity classifications [2], the current guidelines of the European Association of Urology (EAU) discouraged using the ASA classification as comorbidity measure in candidates for radical cystectomy [7]. The huge differences in 90-day and 5-year competing mortality observed after stratification by the ASA classification after previous stratification by the age-adjusted Charlson score [16] (the tool that is recommended by the EAU guidelines for comorbidity assessment [7]) in patients younger than 80 years suggest that the guideline's discouragement of using the ASA classification should be revised for this subset of patients.
Compared with patients who were 70-79 years of age, octogenarians undergoing radical cystectomy had similar complication rates but increased mortality [17] underlining the need for an identification of vulnerable elderly patients prior to surgery. Furthermore, with a median of 23 months (95\% confidence interval 20-27 months), in a recent large multicenter study, the overall survival rate has been reported to be relatively short octogenarians undergoing radical cystectomy [18]. In the current study, with a median of about 30 months, overall survival was something longer (Fig. 1). In a large octogenarian muscle-invasive bladder cancer sample including various types of management, in contrast to the current study comorbidity measured by the Charlson score was an independent predictor of overall mortality with a moderate association with mortality [18]. The inclusion of more impaired patients (only 26\% underwent radical cystectomy [18]), an under-recording of less severe conditions in a multicenter cancer registry [18] and a larger sample size may be discussed as possible explanations for these differing findings.

It is conceivable that self-selection by accumulation of minor forms of chronic -diseases during the long life span and the elimination of severe life-threatening forms by premature mortality might diminish the prognostic significance of individual comorbid conditions in octogenarians. In geriatric patients undergoing emergency general surgery, in contrast to age and ASA classification frailty assessed by the Rockwood frailty index predicted postoperative and major complications [19]. Although it would be of interest, few data is available on the role of frailty assessment in elderly candidates for radical cystectomy until now [5]. 
This study has several limitations. The number of patients aged 80 years or older was limited. Concerning 90-day mortality, the number of events in this subgroup did not allow an analysis with a multitude of variables. Possibly, a multicenter approach including a huge number of octogenarians with well documented clinical data would be promising in order to identify factors other than age and comorbidity that could be associated with outcome in elderly candidates for radical cystectomy [20]. This study was focused on mortality; minor degree complications were not taken into consideration. 90-day mortality in octogenarians undergoing radical cystectomy is higher outside of academic centers [4]. It is possible that different results could be obtained outside an academic setting. Finally, it should be kept in mind that this analysis was based on patients selected for radical cystectomy; the results may not necessarily be extrapolated to a less strictly selected sample of elderly patients.

\section{Conclusions}

This data suggest that extrapolations of perioperative mortality or long-term mortality risks of younger patients to octogenarians selected for radical cystectomy should be used with caution. Cystectomy should not be denied in octogenarians by numeric comorbidity. Concerning 90-day mortality, in octogenarians selected for radical cystectomy chronological age could have greater impact than numeric comorbidity.

\section{Abbreviations \\ ASA: American Society Association physical status classification: \\ CCS: Classification of angina pectoris of the Canadian Cardiovascular Society; Cl: confidence interval; HR: Hazard ratio; NYHA: Classification of cardiac insufficiency of the New York Heart Association; OR: Odds ratio}

\section{Acknowledgements}

The authors thank Dipl.-Med. C. Werner, Regionales Klinisches Krebsregister Dresden (Regional Clinical Cancer Registry Dresden) for providing follow-up data.

\section{Availability of data and materials}

The datasets used and/or analyzed during the current study are available from the corresponding author on reasonable request.

\section{Authors' contributions}

MF, RK and MPW were responsible for the concept and framework of the paper. MF, RK, MH, UH, VN, SZ, OWH and MPW participated in collecting and evaluating the data. MF wrote the paper. MF, RK, MH and MPW were largely responsible for the drafting and final editing. All authors read and approved the final manuscript.

\section{Ethics approval and consent to participate}

Institutional review board approval was obtained (Ethikkommission des Universitätsklinikums Dresden, EK84032009).

\section{Consent for publication}

Not applicable.

\section{Competing interests}

Competing financial interests: The authors declare that they have no competing interests..

\section{Publisher's Note}

Springer Nature remains neutral with regard to jurisdictional claims in published maps and institutional affiliations.

\section{Author details}

'Department of Urology, University Hospital Carl Gustav Carus, Technische Universität Dresden, Fetscherstrasse 74, D-01307 Dresden, Germany. ${ }^{2}$ Department of Medical Statistics and Biometry, University Hospital Carl Gustav Carus, Technische Universität Dresden, Fetscherstrasse 74, D-01307 Dresden, Germany. ${ }^{3}$ Department of Anesthesiology, University Hospital Carl Gustav Carus, Technische Universität Dresden, Fetscherstrasse 74, D-01307 Dresden, Germany. ${ }^{4}$ Department of Urology, University of Rostock, Ernst-Heydemann-Strasse 6, D-18055 Rostock, Germany.

Received: 1 November 2017 Accepted: 4 October 2018

Published online: 22 October 2018

\section{References}

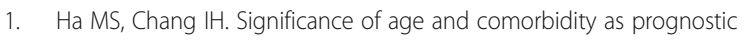
indicators for patients with bladder cancer. Asian J Androl. 2010;12:766-74.

2. Chang SS, Bochner BH, Chou R, Dreicer R, Kamat AM, Learner SP, et al. Treatment of non-metastatic mucle-invasive bladder cancer: AUA/ASTRO/ SUO guideline. J Urol. 2017;198:552-9.

3. Hounsome LS, Verne J, McGrath JS, Gillatt DA. Trends in operative caseload and mortality rates after radical cystectomy for bladder cancer in England for 1998-2010. Eur Urol. 2015;67:1056-62.

4. Zakaria AS, Santos F, Tanguay S, Kassouf W, Aprikian AG. Radical cystectomy in patients over 80 years old in Quebec: a population-based study of outcomes. J Surg Oncol. 2015;111:917-22.

5. Fonteyne $V$, Ost P, Bellmunt J, Droz JP, Mongiat-Artus P, Inman B, et al. Curative treatment for muscle invasive bladder cancer in elderly patients: $A$ systematic review. Eur Urol. 2017;73(1):40-50 [Epub ahead of print].

6. De Groote R, Gandaglia G, Geurts N, Goossens M, Pauwels E, D'Hondt F, et al. Robot-assisted radical cystectomy for bladder cancer in octogenarians. J Endourol. 2016;30:792-8.

7. Witjes AJ, Lebret T, Compérat EM, Cowan NC, De Santis M, Bruins HM, et al. Updated 2016 EAU guidelines on muscle-invasive and metastatic bladder cancer. Eur Urol. 2017;71:462-75.

8. Donat SM, Siegrist T, Cronin A, Savage C, Milowsky MI, Herr HW. Radical cystectomy in octogenarians--does morbidity outweigh the potential survival benefits? J Urol. 2010;183:2171-7.

9. Hollenbeck BK, Miller DC, Taub D, Dunn RL, Underwood W 3rd, Montie $J$, et al. Aggressive treatment for bladder cancer is associated with improved overall survival among patients 80 years old or older. Urology. 2004;64:292-7.

10. Charlson ME, Pompei $P$, Ales $K L$, Mackenzie CR. A new method of classifying prognostic comorbidity in longitudinal studies: development and validation. J Chronic Dis. 1987:40:373-83.

11. American Society of Anesthesiologists: American Society of Anesthesiologists physical status classification system. Available at website http://www.asahq.org/resources/clinical-information/asa-physical-statusclassification-system (Accessed 31 Oct 2017).

12. Chang CM, Yin WY, Wei CK, Wu CC, Su YC, Yu CH, et al. Adjusted ageadjusted Charlson comorbidity index score as a risk measure of perioperative mortality before cancer surgery. PLoS One. 2016;11:e0148076.

13. Boorjian SA, Kim SP, Tollefson MK, Carrasco A, Cheville JC, Thompson RH, et al. Comparative performance of comorbidity indices for estimating perioperative and 5-year all cause mortality following radical cystectomy for bladder cancer. J Urol. 2013;190:55-60.

14. Aziz A, May M, Burger M, Palisaar RJ, Trinh QD, Fritsche HM, et al. Prediction of 90-day mortality after radical cystectomy for bladder cancer in a prospective European multicenter cohort. Eur Urol. 2014;66:156-63.

15. Williams SB, Huo J, Chu Y, Baillargeon JG, Daskivich T, Kuo YF, et al. Cancer and all-cause mortality in bladder cancer patients undergoing radical cystectomy: development and validation of a nomogram for treatment decision-making. Urology. 2017;110:76-83.

16. Charlson M, Szatrowski TP, Peterson J, Gold J. Validation of a combined comorbidity index. J Clin Epidemiol. 1994;47:1245-51.

17. Haden TD, Prunty MC, Jones AB, Deroche CB, Murray KS, Pokala N. Comparative perioperative outcomes in septuagenarians and octogenarians undergoing 
radical cystectomy for bladder cancer - do outcomes differ? Eur Urol Focus. 2017. https:/doi.org/10.1016/j.euf.2017.08.005 [Epub ahead of print].

18. Fischer-Valuck BW, Rao YJ, Rudra S, Przybysz D, Germino E, Samson P, et al. Treatment patterns and overall survival outcomes of octogenarians with muscle invasive cancer of the bladder: an analysis of the National Cancer Database. J Urol. 2018;199:416-23.

19. Joseph B, Zangbar B, Pandit V, Fain M, Mohler MJ, Kulvatunyou N, et al. Emergency general surgery in the elderly: Too old or too frail? J Am Coll Surg. 2016;222:805-13.

20. Schiffmann J, Gandaglia G, Larcher A, Sun M, Tian Z, Shariat SF, et al. Contemporary 90-day mortality rates after radical cystectomy in the elderly. Eur J Surg Oncol. 2014;40:1738-45.

21. Canadian Cardiovascular Society. Canadian cardiovascular society grading of angina pectoris. Website: http://www.ccs.ca/images/Guidelines/Guidelines_ POS_Library/Ang_Gui_1976.pdf. Accessed 31 Oct 2017.

22. The Criteria Committee of the New York Heart Association. Nomenclature and criteria for diagnosis of diseases of the heart and great vessels. 9th ed. Boston: Little, Brown \& Co; 1994. p. 253-6.

Ready to submit your research? Choose BMC and benefit from:

- fast, convenient online submission

- thorough peer review by experienced researchers in your field

- rapid publication on acceptance

- support for research data, including large and complex data types

- gold Open Access which fosters wider collaboration and increased citations

- maximum visibility for your research: over $100 \mathrm{M}$ website views per year

At $\mathrm{BMC}$, research is always in progress.

Learn more biomedcentral.com/submissions 